\title{
Sub-micron X-ray Computed Tomography for Non-Destructive 3D Visualization and Analysis
}

\author{
J. Gelb, M. Feser, A. Tkachuk, G. Hsu, S. Chen, H. Chang, T. Fong, L. Hunter, I. Goldberger, S. \\ H. Lau, W. Yun \\ Xradia, Inc., 5052 Commercial Cir, Concord, CA 94520
}

$\mathrm{X}$-ray computed tomography (XCT) is a rapidly growing field of non-destructive 3D inspection, offering a new approach for high-resolution imaging when visible-light and electron microscopy are insufficient. Using other techniques, 3D visualization is either technologically challenging or requires the sample to be consumed in the image-collection process. By utilizing the high penetration of $\mathrm{x}$-rays coupled with novel techniques in instrumentation, 3D volumes well below the surface of the sample may be collected with micron- and sub-micron spatial resolution.

While XCT has been in use for quite some time, traditional approaches have led to performance limitations. In the most common technique, x-rays project through the sample onto the detector in a cone-beam geometry, typically limiting resolution to the size of the x-ray source. Highresolution imaging is thus achieved by placing the sample very close to the source, which may restrict sample size for tomography to a very small volume [1]. By increasing the resolution of the detection system, however, source-to-sample distances may be relaxed while still achieving resolution of $\sim 1 \mu \mathrm{m}$. Source instabilities are much less influential in this scheme, permitting fast, high-resolution 3D tomography utlizing a larger spot size [1-2].

By pairing x-ray optical elements with a high-resolution detector, theoretical imaging resolution becomes a function only of the optical elements in use and not the x-ray source [1-3]. Such a geometry employs a high-efficiency reflective capillary $\mathrm{x}$-ray condenser lens matched to a Fresnel zone plate objective, similar in design to a transmission light or electron microscope [4, 7-8]. Penetration depth may be optimized through proper selection of x-ray source, either through tuning the photon energy of a synchrotron monochromator or choosing the appropriate target material with a laboratory source. Using an emission line of $8 \mathrm{keV}$, for example, penetration through $100 \mu \mathrm{m}$ of silicon or $300 \mu \mathrm{m}$ of polymer may be obtained, allowing visualization far below the surface of a sample as compared to other techniques. Spatial resolution below $40 \mathrm{~nm}$ has been routinely achieved in this configuration and may be customized simply by changing zone plate objectives [3]. While low-density specimens often produce low xray absorption contrast with $8 \mathrm{keV}$ photons, new developments in Zernike phase contrast imaging highlight material interfaces, thus enabling clear 3D imaging of such specimens [4-6].

The applications for high- and ultra-high resolution XCT range from materials research to biological studies and extend into the semiconductor industry. This technique is not intended to replace other methods, but more to complement them for situations in which they are not suitable (e.g., quantitative porosity measurements). A multi-length-scale system is presented here, and example applications of non-destructive 3D x-ray imaging with micron- and sub-micron resolution are demonstrated. 
References

[1] M. Feser, J. Gelb, H. Chang, H. Cui, F. Duewer, S. H. Lau, A. Tkachuk and W. Yun, "Submicron Resolution CT For Failure Analysis and Process Development", (submitted for publication).

[2] A. Tkachuk, F. Duewer, H. Cui, M. Feser, S. Wang and W. Yun, "X-ray Computed Tomography in Zernike Phase Contrast Mode at $8 \mathrm{keV}$ with 50-nm Resolution using $\mathrm{Cu}$ Rotating Anode X-ray Source", Z. Kristallogr. 222 (2007) 650-655.

[3] Y. S. Chu, J. M. Yi, F. De Carlo, Q. Shen, Wah-Keat Lee, H. J. Wu, C. L. Wang, J. Y. Wang, C. J. Liu, C. H. Wang, S. R. Wu, C. C. Chien, Y. Hwu, A. Tkachuk, W. Yun, M. Feser, K. S. Liang, C. S. Yang, J. H. Je, and G. Margaritondo, "Hard-X-ray Microscopy with Fresnel Zone Plates Reaches 40 nm Rayleigh Resolution”, Appl. Phys. Lett. 92 (2008) 103119.

[4] M. Young, "Zone Plates and Their Aberrations", J. Opt. Soc. Of Am. 62.8 (1972) 972-976.

[5] Nikon MicroscopyU: Phase Contrast Microscopy - Introduction. Available from: http://www.microscopyu.com/articles/phasecontrast/phasemicroscopy.html

[6] F. Zernike, "Das Phasenkontrastverfahren bei der mikroskopischen Beobachtung", Zeitschrift für technische Physik 36 (1935) 848-851.

[7] Y. Feng, M. Feser, A. Lyon, S. Rishton, X. Zeng, S. Chen, S. Sassolini and W. Yun, "Nanofabrication of High Aspect Ratio $24 \mathrm{~nm}$ X-ray Zone Plates for X-ray Imaging Applications", J. Vac. Sci. Technol. B 25 (2007) 2004.

[8] X. Zeng, F. Duewer, M. Feser, C. Huang, A. Lyon, A. Tkachuk and W. Yun, "Ellipsoidal and Parabolic Glass Capillaries as Condensers for X-Ray Microscopes”, Appl. Opt. 47 (2008) 2376-2381.

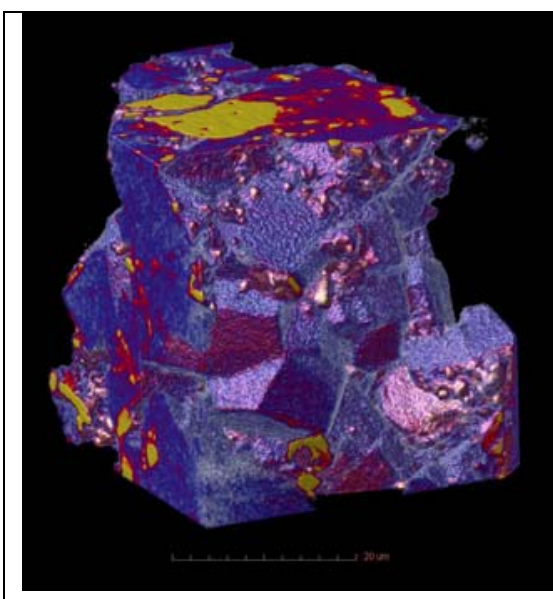

(a)

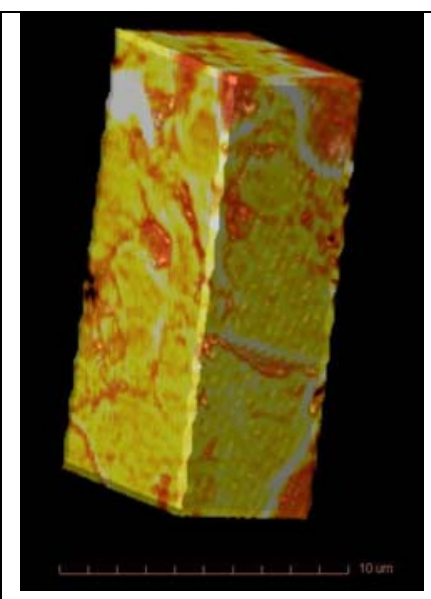

(b)

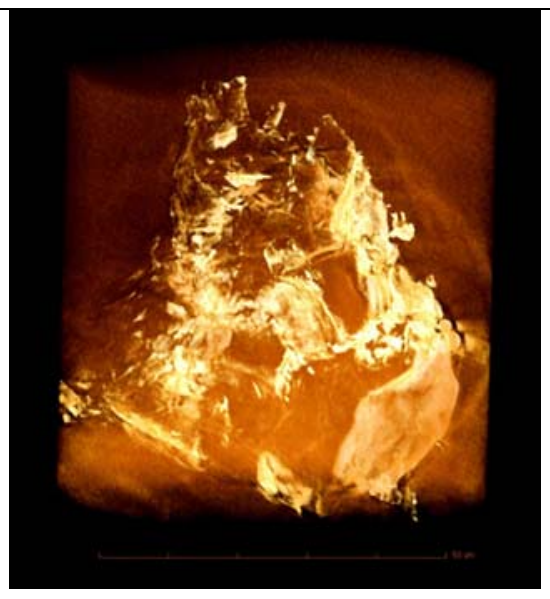

(c)

Fig. 1 Three volume-rendered examples of 3D x-ray computed tomography with submicron resolution are shown here with brighter colors representing higher contrast.

(a) shows an aluminum-hydroxide matrix containing sub-micron iron-oxide particles, (b) a porous shale rock, and (c) compacted cellulose powder (imaged with Zernike phase contrast to enhance the material interfaces). 